Available online at GSC Online Press Directory

GSC Biological and Pharmaceutical Sciences

e-ISSN: 2581-3250, CODEN (USA): GBPSC2

Journal homepage: https://www.gsconlinepress.com/journals/gscbps

(RESEARCH ARTICLE)

\title{
Assessment of genetic diversity among different sugarcane genotypes using internal transcribed spacer (ITS) region of the ribosomal DNA (rDNA)
}

\author{
Jomhe Farsangi Forough 1,2, Thorat Avinash Shivaji ${ }^{2}$ and Devarumath Rachayya Mallikarjun 1,2* \\ ${ }^{1}$ Molecular Biology and Genetic Engineering Section, Vasantdada Sugar Institute, Manjari (Bk), Pune, India-412307. \\ ${ }^{2}$ Department of Biotechnology, Savitribai Phule, Pune University, Pune, India-411007.
}

Publication history: Received on 29 September 2018; revised on 09 October 2018; accepted on 15 October 2018

Article DOI: https://doi.org/10.30574/gscbps.2018.5.2.0108

\begin{abstract}
Internal transcribed spacer or ITS region of nuclear ribosomal DNA (rDNA) has been used to evaluate genetic assortment and phylogenetic relationship in nine sugarcane genotypes including Saccharum species and another related genus as Erianthus, Narenga and hybrid. DNA was extracted from selected genotypes and ITS (ITS-1 and ITS-2) regions were amplified using specific primers. The sequence lengths ITS-1 showed 205- $207 \mathrm{bp}$, while ITS2 was ranged from 211- 218 bp. However, G+C content (\%) 65.2\% - 67\% in ITS-1 and in ITS-2 68.4\% - 99.7\%. The sequence lengths of fragment and GC content of ITS-1 and ITS-2 regions showed variable. To evaluate the phylogenetic association of both the region of ITS (ITS-1 and ITS-2) neighbor-joining (NJ) method was employed. The cluster A of ITS- 1 and cluster B for ITS- 2 and cluster C combined between ITS1+ ITS2 sequences gave two distinct groups A and B. The group A represented the ITS1 sequences which showed two subgroups I and II. The A-I subgroup consisted of wild species of sugarcane; Erianthus, Narenga and S. robustum, whereas the A-II subgroup consisted of the Saccharum species and hybrid. The ITS2 sequences in the group B showed better correlation amongst each other. The sequences ITS- 1 \& ITS- 2 combined and compared with some selected sequences from NCBI database using NJ method. The results have confirmed that ITS region can be used for evaluating the genetic assortment in Saccharum and its closely related genes.
\end{abstract}

Keywords: Genetic diversity; ITS; rDNA; PCR; Sugarcane

\section{Introduction}

Sugarcane (Saccharum spp. hybrids) is secure second rank an imperative crop and acting as significant role in agricultural and industrial economy [1], provides more than $70 \%$ sugar and more than $30 \%$ ethanol production in tropical and subtropical countries [2-5]. Currently, sugarcane is cultivated in 20.42 million ha producing 1,333.2 million tonnes with an average cane productivity of 65.20 tonnes/ha [6]. Sugarcane belongs to family Poaceae tribe Andropogoneae.

Present sugarcane cultivars are highly polyploidy in nature and often aneuploid, (2n=100-130) [7-8]. The Saccharum genus having six spp. viz., the noble cane $S$. officinarum L. two wild spp. Including $S$. spontaneum L. and $S$. robustum Brandes et Jeswiet ex Grassl, and three sub spp., S. sinense Roxb., S. barberi Jeswiet., and S. edule Hassk. And four other sugarcane genus including Erianthus Michx., Narenga Burkiee., Miscanthus Anderss., and Sclerostachya. For the evolutionary relationships among species in Saccharum complex, it is still unclear although researchers have attempted to disclose the phylogenetic relationships of Saccharum complex using molecular markers, plastid intergenic spacers, and ITS of nrDNA [9-10].

\footnotetext{
${ }^{*}$ Corresponding author

E-mail address: rdevarumath@gmail.com
} 
Jomhe et al. / GSC Biological and Pharmaceutical Sciences 2018, 05(02), 017-025

Universally in the entire organism gene coding is available for ribosomal DNA. The tremendous importance of the restriction fragment and sequence analysis of nuclear rDNA as a reliable approach for addressing the genomic relationships among cultivated species and its wild relatives has been well recognized [11-12]. Nucleotide sequences of ITS $(1,2)$ of $18 \mathrm{~S}$ to26S $\mathrm{nr}$ DNA has proved to be helpful in taxonomic studies [13-14]. Then rDNA-ITS have been used in the evolutionary analysis of inter or intraspecific genetic variation and due to elevated rate of mutation it is also used in selection of parent in breeding program in different plants [15-17] and in sugarcane $[10,18]$. The length of ITS regions and its sequences of rDNA repeats are considered to be quickly developing and hence may differ. Widespread PCR primers of ITS regions are developed from extremely conserved flanking regions, and comparatively, small size enables easy amplification of ITS region (600-700 bp) of rDNA repeats. To evaluate the ITS regions small quantity of DNA are necessary and it is easy to produce, quick and this whole thing makes the ITS region an exciting topic for phylogenetic and evolutionary investigations [13; 19] and additionally for biogeographic studies [20-23]. The present investigation was to study the genetic diversity and phylogenetic relationship on the basis of ITS regions (ITS1 and ITS2) in sugarcane genotypes.

\section{Material and methods}

\subsection{Plant material}

Fresh plant material (young leaves) of Saccharum genotypes and other related genus from the farm of Vasantdada Sugar Institute, Manjari (Bk), Pune and Sugarcane breeding Centre, Amboli, including 9 sugarcane clone namely Vellai (Saccharum officinarum); IJ-76-417(Saccharum robustum); Holes (Saccharum spontaneum); Dhaur Alig (Saccharum barberi); IK-76-91 (Erianthus arundinaceus); E. ciliaris, E. elegans, Narenga porphyrocoma and CoC 671 sugarcane cultivar were selected for the experiment (Table. 1).

\subsection{DNA isolation and PCR amplification of ITS regions}

Collected leaves were frozen in liquid nitrogen and kept in $-80^{\circ} \mathrm{C}$ for preservation. The total genomic DNA was isolated from each stored sample by using the CTAB method with little modification [24]. The quantity and quality of extracted DNA were evaluated by UV spectrophotometric method and agarose gel electrophoresis. The final working concentration of DNA was diluted at $10 \mathrm{ng} / \mu \mathrm{L}$ was used in PCR.

The PCR was carried out by using specific primers of ITS-1 (5'-GCT GCG TTC TTC ATC GAT GC- 3' and 5'-GGA AGT AAA AGT CGT AAC AAG G- 3') and ITS-2 (5'-GCA TCG ATG AAG AAC GCA GC-3' and 5'-TCC TTC CGC TTA TTG ATA TGC-3') regions [25]. These primers are used in equal ratio. Amplification of genomic DNA was carried out using thermal cycler (Applied BioSystems) and the reaction mixture volume of $50 \mu \mathrm{L}$ consisting of sterilized glycerol $(5 \mu \mathrm{L}), 10 \times \mathrm{Taq}$ buffer $(10 \mu \mathrm{L}), 2 \mathrm{mM}$ dNTPs $(5 \mu \mathrm{L}), 25 \mathrm{mM} \mathrm{MgCl} 2(6 \mu \mathrm{L}), 1 \mathrm{U}$ Taq DNA Polymerase $(0.4 \mu \mathrm{L}), 10 \mu \mathrm{M}$ ITS- 1 and ITS-2 primers $(20$ $\mu \mathrm{L}$ ) (Sigma, USA) and of $40 \mathrm{ng}$ template DNA $(4 \mu \mathrm{L}$ )and programmed for 40 cycles were as follows; 1 min primer annealing at $48{ }^{\circ} \mathrm{C}, 45 \mathrm{~s}$ extension at $72^{\circ} \mathrm{C}$, and a final extension of $10 \mathrm{~min}$ at $72{ }^{\circ} \mathrm{C}$. PCR products were resolved on $3 \%$ $(w / v)$ agarose gel electrophoresis (AGE) with $1 \times \mathrm{TAE}$ buffer, stained with EtBr and documented under UV transilluminator (UViTech).

\subsection{Cloning and sequencing of ITS regions}

The amplified PCR product was eluted and purified by using gene clean kit (Gene Clean II, Bio 101) by following manufacturer instructions. The isolated purified product was introduced in GMT vector (Promega) followed by transformed in E. coli (DH5 $\alpha$ ) and identified through blue/white screening as well as confirmed by PCR and sequencing of clones (minimum three) of every species were carried out in the sense and antisense direction.

\subsection{Sequence and phylogenetic analysis}

The sequences of ITS region obtained from the sugarcane varieties were subjected to sequencing and the raw sequences were edited and verified for vector sequence contamination followed by the sequence alignment and phylogeny analysis of final edited sequences. The sequence alignment was obtained using the ClustalW algorithm [26]. The BioEdit software provided the graphic view of the sequence alignment generated. The sequence alignment assignment provided a brief description of our ITS sequences and the database sequences in terms of sequence identity and gap percentage and Evalue notes through the NCBI, BLAST analysis. The phylogeny software, MEGA6 [27-29] provided comparative analyses of our ITS sequences and that of the NCBI database ITS sequences. The phylogeny was generated using the MEGA6.0 software using Neighbor-Joining method (1000 bootstraps) [30]. 


\section{Results}

\subsection{ITS-1 and ITS-2 sequences of nrDNA}

All the amplified product from nine sugarcane are sequenced and have been submitted to nucleotide sequence database (EMBL) under the accession number LT220885 to LT220902.

\subsection{PCR amplification of ITS-1 and ITS- 2 regions}

PCR amplification of the rDNA-ITS (ITS1 and ITS2) region produced one major band approximately 300 bp (ITS1) and 350 bp (ITS2) (Figure 1 A-B).
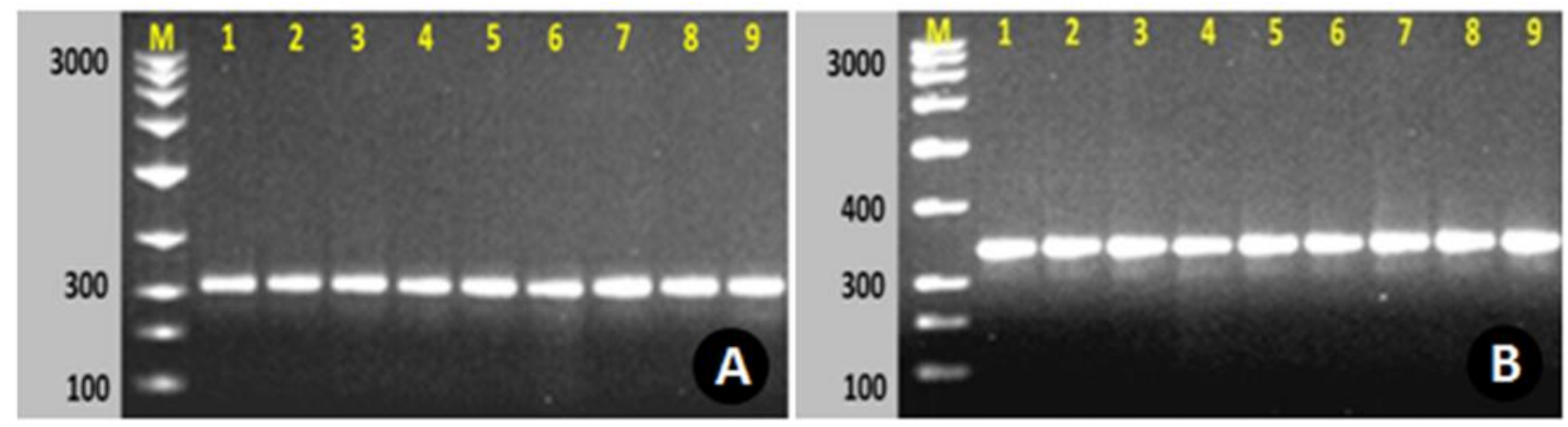

Figure 1 PCR amplification of ITS-1 and ITS-2 (M: DNA marker; 1-9 genotypes of sugarcane mentioned in Table 1)

\subsection{Sequence length analysis of ITS -1 and ITS-2 and G+C content}

All nine amplified ITS regions produce an inconsistent site, lengths, and percentage of GC content. The sequence lengths of ITS-1 ranged from 205 to $207 \mathrm{bp}$, while ITS-2 was ranged from 211 to $218 \mathrm{bp}$. However, the percentage of GC content is slightly lower in the ITS-1 region (65.2 to $67 \%$ ) compared to the ITS-2 region (68.4 to 99.7\%) (Table 1).

Table 1 Length and G+C\% content in the ITS1 and ITS2 regions of nine sugarcane genotypes used in this study

\begin{tabular}{llllcccc}
\hline \multirow{2}{*}{ Sr. No. } & \multirow{2}{*}{ Genotypes } & \multirow{2}{*}{ Clone } & Status & \multicolumn{2}{c}{ ITS1 } & \multicolumn{2}{c}{ ITS-2 } \\
\cline { 5 - 7 } & & & & Length & G+C\% & Length & G+C\% \\
\hline 1 & So & Vellai & Wild & 207 & 65.7 & 214 & 70.6 \\
2 & Sr & IJ-76-417 & Wild & 206 & 66.5 & 215 & 68.4 \\
3 & Ss & Holes & Wild & 207 & 65.7 & 215 & 70.7 \\
4 & Sb & Dhaur Alig & Wild & 207 & 66.2 & 215 & 70.7 \\
5 & Ea & IK-76-91 & Wild & 206 & 67.0 & 213 & 71.4 \\
6 & Ec & - & Wild & 205 & 66.8 & 213 & 72.4 \\
7 & Ee & - & Wild & 206 & 66.0 & 211 & 71.6 \\
8 & Np & - & Wild & 207 & 65.2 & 218 & 99.7 \\
9 & Cv & CoC 671 & Cultivated & 207 & 66.7 & 215 & 70.7 \\
\hline
\end{tabular}

Note: So- Saccharum officinarum; Sr- S. robustum; Sp- S. spontaneum; Sb- S. barberi; Ea- Erianthus arundinaceus; Ec- E. ciliaris; Ee- E. elegans; NpNarenga porphyrocoma; Cv- Hybrid

\subsection{Sequence alignment and phylogenetic analysis of ITS-1 and ITS-2}

The sequence alignments of ITS-1 and ITS-2 generated by ClustalW showed the variable sites like T-A and C-G mismatch base insertion or base deletion and C-T and G-A transversion, as shown in Figure 2. The phylogenetic relationship of all nine sugarcane genotypes was carried out for ITS-1 and ITS-2 sequences using Neighbor-Joining method and combined nucleotide sequences data of ITS1 + ITS2 (Figure 3 A-C). Some of the sequences downloaded from NCBI database generated dendrogram for the comparison study with some sugarcane species and related genera as shown in (Figure $4 \mathrm{~A}-\mathrm{C})$. 


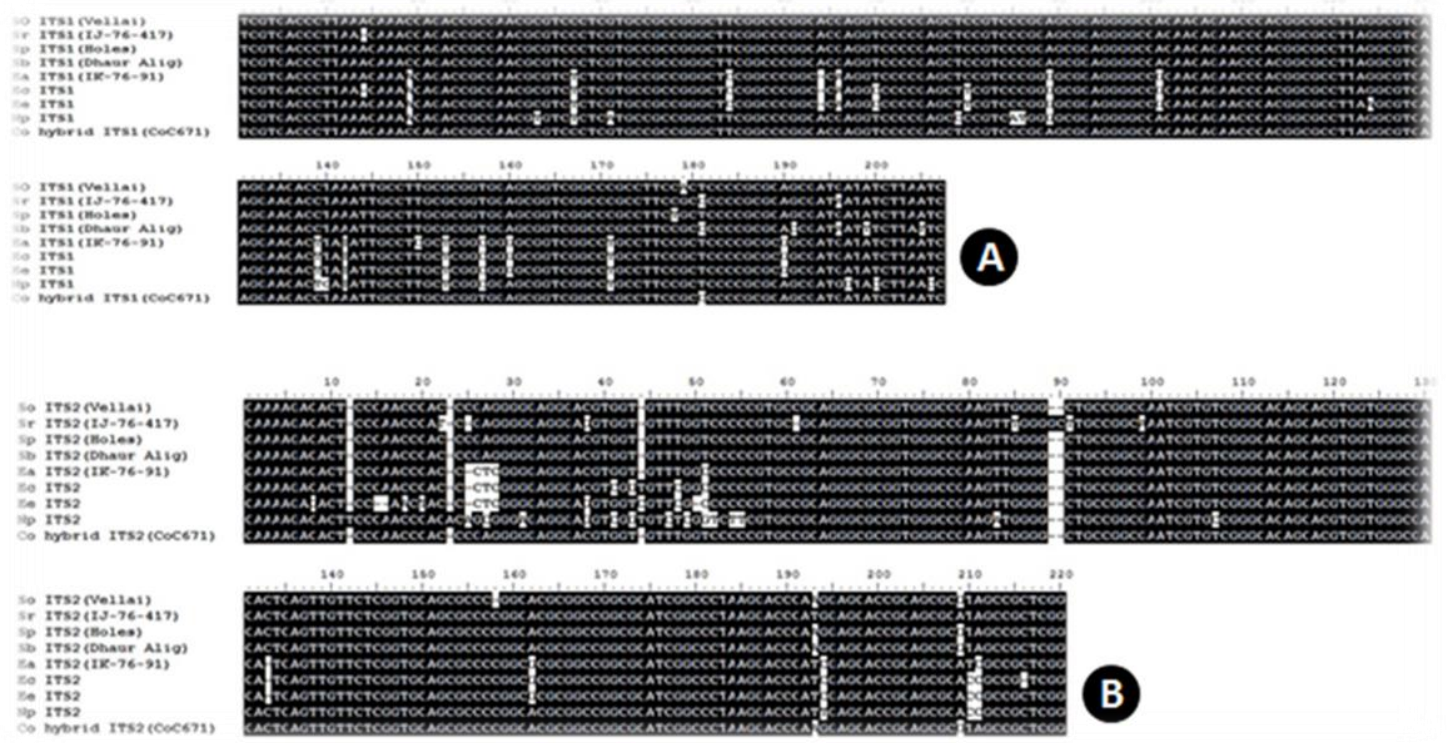

Figure 2 Sequence alignment among the ITS-1 (A) and ITS-2 (B) Code for the sugarcane genotypes as given in Table 1
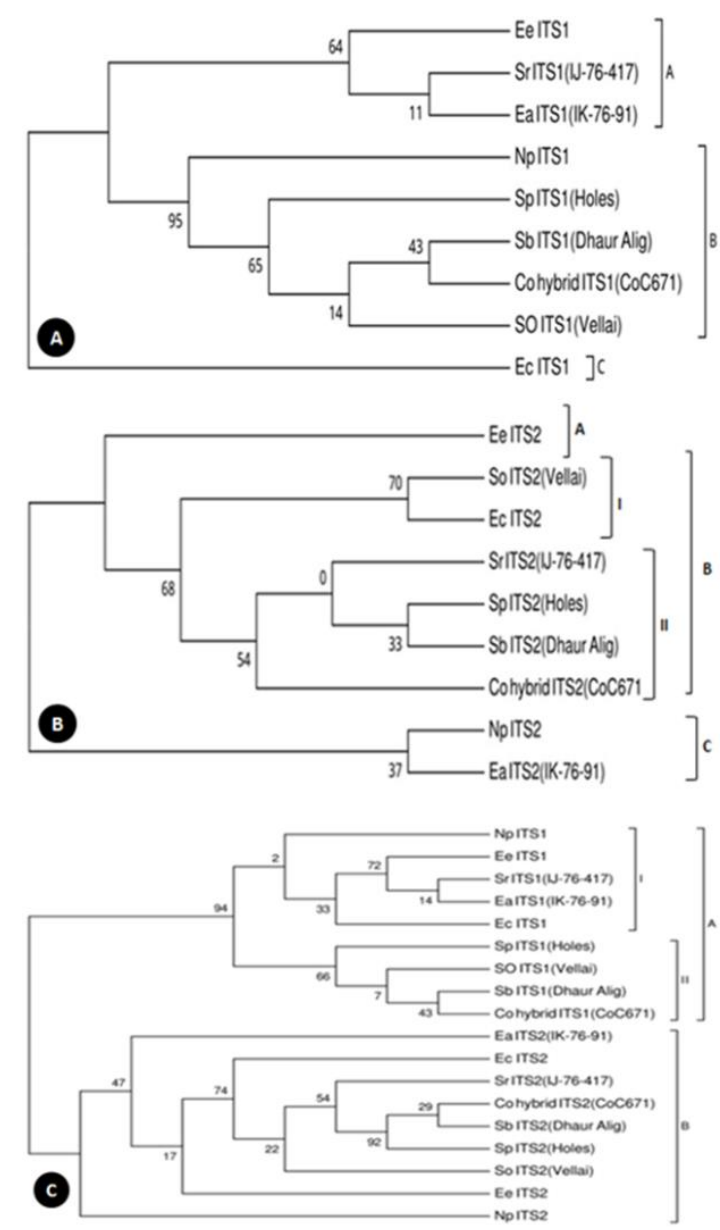

Figure 3 Phylogenetic tree of sugarcane genotypes based on ITS-1 (A), ITS-2 (B) and combined ITS-1+ITS-2 (C) sequences

The phylogeny tree generated between the ITS-1 sequences revealed 3 groups; A, B and C. The A group comprised of the Erianthus species, the Saccharum series were clustered in group B and the C group was left only with the Erianthus 
cilliaris which showed a correlation with that of group A (Figure 3A). The phylogeny tree of ITS2 sequences showed better correlation amongst each other (Figure 3B). The phylogeny between combined ITS1 + ITS2 sequences gave two distinct groups A and B. The group A represented the ITS1 sequences which showed two subgroups I and II. The A-I subgroup consisted of wild species of sugarcane; Erianthus, Narenga and S. robustum, whereas the A-II subgroup consisted of the Saccharum species. The ITS2 sequences in the group B showed better correlation amongst each other (Figure 3C).

The Phylogeny of ITS (ITS-1, ITS-2, and ITS-1 + ITS-2) sequences both our sequences and other research group submitted sequences taken from NCBI database were used to study the phylogenetic relationship between sugarcane genotypes with some related species consider as out-group. The dendrogram clustered into 4 groups of (A, B, C, and D). The group A clustered the Erianthus species with the S. robustum and Saccharum arundinaceus. The group B consisted of Narenga, S. officinarum, S. spontaneum, S. officinarum hybrid and S. barberi which showed better clustering with Zea perennis, Saccharum fallax, S. robustum, S. barberi and S. spontaneum; whereas the group C formed a different group with Miscanthus and Zea mays. The group D showed the separate Saccharum fulvum which relates to the group A (Figure 4A). The phylogeny ITS-2 sequences with their NCBI homology were clustered into 4 groups which clearly reflects that group An Erianthus showed association with the S. barberi and S. robustum ITS-2, group B shows major cluster of our ITS-2 sequences with that of, Saccharum fulvum, S. robustum and Saccharum arundinaceus. The group C showed only Narenga porphyrocoma (ITS-2) to show a relation with Zea mays, S. spontaneum and Narenga porphyrocoma (ITS-2, AF345233), whereas the group D was separated with Miscanthus and Narenga fallax from the other groups (Figure 4B).

The phylogeny generated between the ITS-1 + ITS-2 sequences and their NCBI homologies revealed that ITS1 sequences shown a fair distribution among the homologs whereas the ITS-2 sequences have shown to form a cluster among themselves with Narenga porphyrocoma and Erianthus forming separate groups (Figure 4C).
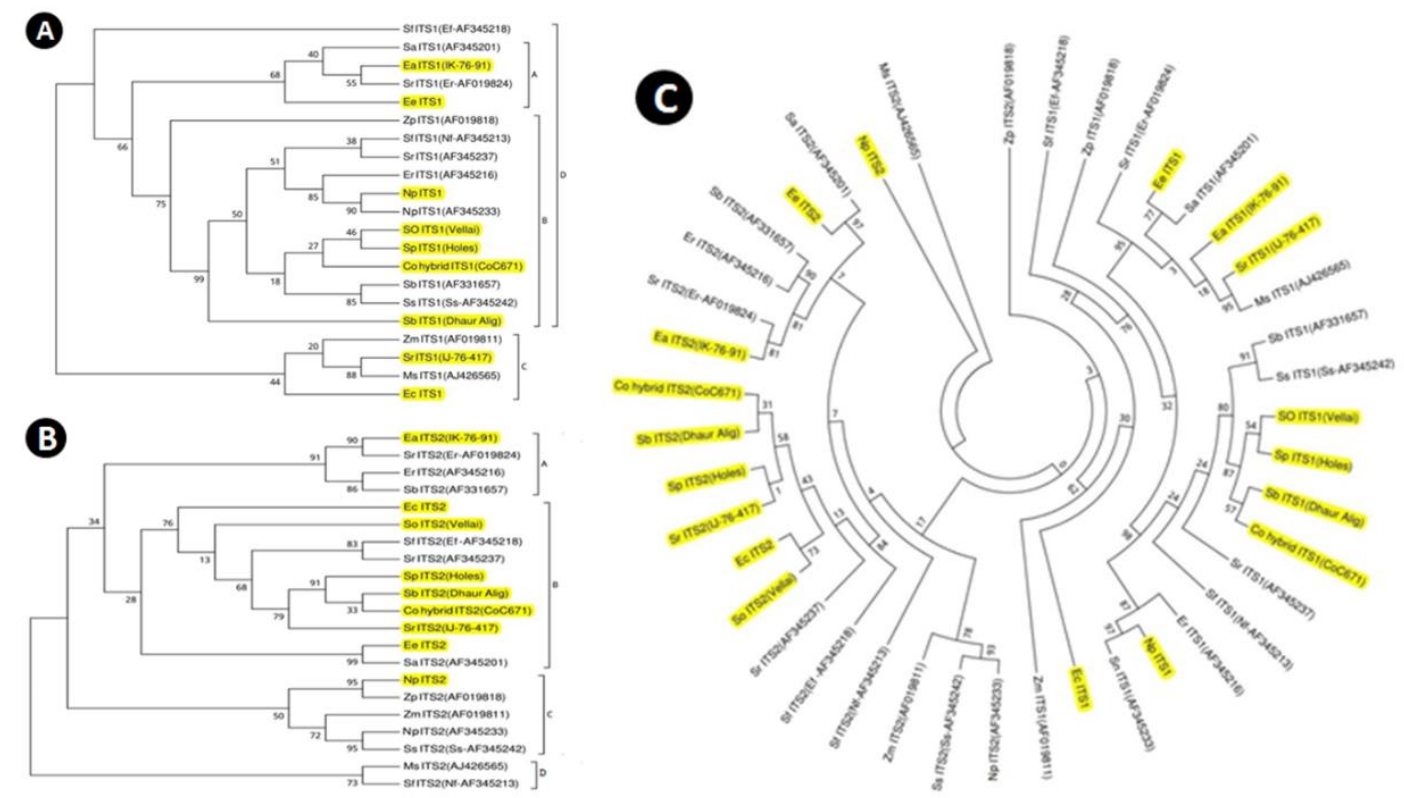

Figure 4 Phylogenetic analysis of sugarcane ITS-1(A), ITS-2 (B) and ITS-1 + ITS-2 (C) sequences with some of the sequences downloaded from NCBI database

[The initials representing the sugarcane ITS1 sequences: So-Saccharum officinarum (vellai); Sr: Saccharum robustum (IK-79-417); Sp: Saccharum spontaneum (Holes); Sb: Saccharum barberi (Dhaur Alig); Ea: Erianthus arundinaceus (IK-76-91); Ec: Erianthus ciliaris; Ee: Erianthus elegans; Np: Narenga; Co: Saccharum officinarum hybrid (CoC671); Er: Erianthus rockii (AF345216); Sa: Saccharum arundinaceus (AF345201); Sb: Saccharum barberi (AF331657); Nf: Narenga fallax (AF345213); Sf: Saccharum fulvum (AF345218); Er: Erianthus ravennae (AF019824); Sr: Saccharum robustum(AF345237); Ss: Saccharum sinense (AF345242); Ms: Miscanthus sinensis (AJ426565); Zp: Zea perennis (AF019818); Zm: Zea may (AF019811); Np: Narenga porphyrocoma (AF345233)].

\section{Discussion}

ITS is the region of 18s-26s nrDNAis consisted of two spacer of ITS-1 and ITS-2 sequences have additional informative sites and it has been extensively utilized to investigate the intra-specific dissimilarity and inter-specific association of plants $[13,15-17,31-34]$. To measure the degree of relatedness in between species, variation in DNA sequences is utilized. Differences in nucleotide sequences can be used to definite the degree of relatedness between spp. [35]. The 
extremely conserved character of 18s and 26s rRNA genes allows alleviate the primer construction and PCR amplification [36], and many investigations have revealed the ITS region to be adequately unpredictable, as a result, it is helpful in providing information to compare taxa at the molecular level. The nrDNA-ITS seem to be a very helpful source of data for considering phylogenetic association within the Saccharum. Internal transcribed spacer regions generally explain the advanced rate of variation that is necessary for extrapolating phylogenies of closely allied species and populations in a known species [36-38]. Very recently [18] studied ITS-nrDNA to identify the genetic divergence and genetic variability of thirty sugarcane genotypes (Saccharum officinarum L.) for exploitation of the potential parent source in sugarcane improvement through breeding. Previously Internal transcribed spacer or nrDNA-ITS region were utilized to identify the intergeneric hybrids of Saccharum spp. $\times$ E. fulvus) [40] and evaluation of phylogenetic as well as the evolution of six Sorghum spp. [41].

In the current investigation, several variable sites were observed, with excellent reproducibility by repeated sequencing can be used as specific DNA fingerprinting sites. Similar kind of results was reported in sugarcane [18]. The sequence of rnDNA-ITS has been used in the genetic relationship analysis of the spp. belong to genus Saccharum and another related genus as Erianthus, Narenga, and hybrid. The result is obtained in the present study have shown that GC percentage is lower in ITS1 compare to ITS2 and also sequence length is longer in ITS-2 region than in ITS-1. A similar result was reported by $[18,42]$, but in the present investigation, the variation sites found higher in ITS-2 region than ITS- 1 as is observed in other plants $[16,43]$. The possible reason behind that the spp. of genus Saccharum are highly complex polyploidy in nature which leads to the divergent evolutionary process of Saccharum as compared to other crops. Therefore, ITS approach can be used for the assessment of the genetic diversity in sugarcane.

The phylogenetic analysis of ITS-1 sequences revealed the Saccharum series were clustered in one group and Erianthus cilliaris was left in the separate group which showed a correlation with Saccharum. The phylogenetic analysis of ITS-2 has shown better correlation amongst species compares to ITS-1. In ITS-2 Narenga porphyrocoma and Erianthus arundinaceus formed one group with $37 \%$ bootstrap values (Fig. 3B). Phylogenetic analysis between the sugarcane ITS1, ITS- 2 and combines sequences and their respective NCBI database showed the ITS- 1 sequences revealed a fair distribution among the groups whereas ITS-2 sequences have shown to form a cluster among Narenga porphyrocoma and Erianthus forming separate groups. Our results are also correlated with phylogenetic tree generated in the investigation of the thirty genotypes of sugarcane [18] obtained that $S$. senseand $S$. barberi species formed a single cluster, and they were situated between $S$. spontaneum and $S$. officinarum. This study supported the hypothesis that $S$. sinense and S. barberi were coming from interspecific hybrid species of S. spontaneumand S. officinarum [44]. According to classification by Irvine [45], derived that S. spontaneum and S. officinarum in two species similar observations in some extent observed in our study it supported by [18]. This conclusion coincided with RAPD, ISSR and SSR markers [46-47]. These results are supported by other marker systems as $r$-DNA spacers [48-49].

\section{Conclusion}

The present study shows that Saccharum and Narenga are closely related group whereas the Erianthus showed significant divergence. These outcomes are supported by other marker systems as r-DNA spacers. The information generated from sequence and its length from ITS region may be a helpful parameter for the evaluation of genetic diversity and phylogenetic studies in sugarcane species.

\section{Compliance with ethical standards}

\section{Acknowledgments}

Authors are gratefully acknowledged the Director-General, VSI, Pune for their invariable support, encouragement and providing infrastructure facilities throughout the research study and also thankful to Breeding Department, VSI for providing plant material.

\section{Disclosure of conflict of interest}

The authors declare that there are no conflicts of interest. Study conception and Design: JFF, RMD, and AST

Acquisition of Data: JFF and AST

Analysis and interpretation of data: JFF, AST, and RMD

Drafting of the manuscript: JFF and AST

Critical revision: RMD 


\section{References}

[1] Thorat AS, Sonone NA, Choudhari VV, Devarumath RM and Babu KH. (2017). Plant regeneration from cell suspension culture in Saccharum officinarum L and ascertaining of genetic fidelity trough RAPD and ISSR markers. 3 Biotech, 7, 16.

[2] Singh RK, Singh RB, Singh SP and Sharma ML. (2011). Identification of sugarcane microsatellites associated to sugar content in sugarcane and transferability to other cereal genomes. Euphytica, 182, 335-354.

[3] Prabu G, Kawar PG, Pagariya MC and Prasad DT. (2011). Identification of water deficit stress upregulated genes in sugarcane. Plant Molecular Biology Reporter, 29, 291-304.

[4] Silva MDA, Jifon JL, Dasilva JAG, Santos CMD and Sharma V. (2012). Relationships between physiological traits and productivity of sugarcane in response to water deficit. Journal of Agricultural Science, 4, 1-15.

[5] Alonso-Pippo W, Lueng CA, Alberteris LAM, Pino GG and Duvoisin Jr. (2013). Practical implementation of liquid biofuels: The transferability of the Brazilian experiences. Energy Policy, 60, 70-80.

[6] Shrivastava AK, Solomon S, Rai RK and Singh P. (2015). Physiological interventions for enhancing sugarcane and sugar productivity. Sugar Tech, 17, 215-226.

[7] Roach BT. (1969). Cytological studies in Saccharum: chromosome transmission in interspecific and intergeneric crosses. Proceeding International Scociety of Sugarcane Technology, 13, 901-920.

[8] Marconi TG, Costa EA, Miranda H and Mancini MC. (2011). Functional markers for gene mapping and genetic diversity studies in sugarcane. BMC Research Notes, 4, 264.

[9] Chen H, Fan YH, Xiang-Yu JG, Cai Q and Zhang YP. (2003). Phylogenetic relationships of saccharum and related species inferred from sequence analysis of the nrDNA ITS region. Acta Agronomica Sinica, 29, 379-385.

[10] Hodkinson TR, Chase MW, Liedo MD, Salamin N and Renvoize SA. (2002). Phylogenetics of Miscanthus Saccharum and related genera (Saccharinae Andropogoneae Poaceae) based on DNA sequences from ITS nuclear ribosomal DNA and plastid trnL intron and trnL-Fintergenic spacers. Journal of Plant Research, 115, 381-392.

[11] Gustafsson L and Gustafsson P. (1994). Low genetic variation in Swedish population of the rare species Vicia Pisiformis (Fabaceae) revealed with rflp (RDNA) and RAPD. Plant Systematics and Evolution, 189, 133-148.

[12] Laurent V, Risterucci AM and Lanaud C. (1993). Variability of nuclear ribosomal genes within Theobroma cacao. Heredity, 71, 96-103.

[13] Baldwin BG, Sanderson MJ, Porter JM, Wojciechowski MF, Campbell CS and Donoghue MJ. (1995). The ITS region of nuclear ribosomal DNA: A valuable source of evidence on angiosperm phylogeny. Annals of the Missouri Botanical Garden, 82, 247-277.

[14] Singh A, Devarumath RM, Rama Rao S, Singh VP and Raina SN. (2008). Assessment of genetic diversity and phylogenetic relationships based on ribosomal DNA repeat unit length variation and internal transcribed spacer (ITS) sequences in chickpea (Cicer arietinum) cultivars and its wild species. Genetic Resources and Crop Evolution, 54, 810-825.

[15] Sultana S, Lim YP, Bang JW and Choi HW. (2011). Internal transcribed spacer (ITS) and genetic variations in Lilium native to Korea. Horticulture Environment and Biotechnology, 52, 502-510.

[16] Dkhar J, Kumaria S, Rama Rao S and Tandon P. (2012). Sequence characteristics and phylogenetic implications of the nrDNA internal transcribed spacers (ITS) in the genus Nymphaeawith afocus on some Indian representatives. Plant Systematics and Evolution, 298, 93-108.

[17] Quan MH, Qu LJ, She CW, Wu XJ and Chen DM. (2012). rDNA internal transcribed spacer sequence analysis of Lycoris Hert. African Journal of Biotechnology, 11, 7361- 7365.

[18] Yang CF, Yang LT, Li YR, Zhang GM, Zhang CY and Wang WZ. (2015). Sequence Characteristics and Phylogenetic Implications of the nrDNA Internal Transcribed Spacers (ITS) in Protospecies and Landraces of Sugarcane (Saccharum officinarum L). Sugar Tech, 18, 8-15.

[19] Hershkovitz MA and Zimmer EA. (1996). Conservation patterns in angiosperm rDNA ITS2 sequences. Nucleic Acid Research, 24, 2857-2867. 
[20] Baldwin BG. (1993). Molecular phylogenetics of Calcydenia (Compositae) based on ITS sequences of nuclear ribosomal DNA: Chromosomal and morphological evolution reexamined. American Journal of Botany, 80, 222238.

[21] Suh Y, Thien LB, Reeve HE and Zimmer EA. (1993). Molecular evolution and phylogenetic implications of ribosomal DNA in Winteraceae. American Journal of Botany, 80, 1042-1055.

[22] Hsiao C, Chatterton NJ, Asay KH and Jensen KB. (1994). Phylogenetic relationships of 10 grass species: an assessment of phylogenetic utility of the internal transcribed spacer region in nuclear ribosomal DNA in monocots. Genome, 37, 112-120.

[23] Dubouzet JG and Shinoda K. (1999). Relationships among old and new world Alliums according to ITS DNA sequence analysis. Theoretical and Applied Genetics, 98, 422-433.

[24] Aljanabi SM, Froget L and Dookun A. (1999). An improved and rapid protocol for the isolation of polysaccharide and polyphenol free sugarcane DNA. Plant Molecular Biology Report, 17, 1-8.

[25] White TJ, Bruns T, Lee S and Taylor J. (1990). Amplification and direct sequencing of fungal ribosomal RNA genes for phylogenetics. In: MA Gelfand DH Sninsky JJ White TJ editors. PCR protocols: A guide to methods and applications. San Diego: Academic Press, 315-332.

[26] Li W, Cowley A, Uludag M, Tamer G and Tamer G. (2015). The EMBL-EBI bioinformatics web and programmatic tools framework. Nucleic Acids Research, 43, 580-584.

[27] Kumar S, Tamura K and Nei M. (1994). MEGA: molecular evolutionary genetics analysis software for microcomputers. Computer Applications in the Biosciences, 10, 189-191.

[28] Tamura K, Peterson D, Peterson N, Stecher G, Nei M and Kumar S. (2011). MEGA5: molecular evolutionary genetics analysis using maximum likelihood evolutionary distance and maximum parsimony methods. Molecular Biology and Evolution, 28, 2731-2739.

[29] Tamura K, Stecher G, Peterson D, Filipski A and Kumar S. (2013). MEGA6: Molecular Evolutionary Genetics Analysis Version 60. Molecular Biology and Evolution, 30, 2725-2729.

[30] Shingote PR, Kawar PG, Pagariya MC, Kuhikar RS, Thorat AS and Babu KH. 92015). SoMYB18 a sugarcane MYB transcription factor improves salt and dehydration tolerance in tobacco. Acta Physiologiae Plantarum, $37,217$.

[31] Wojciechowski MF, Sanderson MJ, Baldwin BG and Donoghue MJ. (1993). Monophyly of aneuploid Astragalus (Fabaceae) evidence from nuclear ribosomal DNA internal transcribed spacer sequences. American Journal of Botany, 80, 711-722.

[32] Sanderson MJ and Wojciechowski MF. (1996). Diversification rates in a temperate legume clade: are there so many species of Astragalus (Fabaceae). American Journal of Botany, 83, 1488-1502.

[33] Delgado-Salinas A, Turley T, Richman A and Lavin M. (1999). Phylogenetic analysis of cultivated and wild species of Phaseolus (Fabaceae). Systematic Botany, 23, 438-460.

[34] Zhang ZX, Lin SZ and Xue X. (2009). Phylogenetical relationship of five Ericaulon species based on the ITS sequences. Journal of Beijing Forestry University, 29, 1-6.

[35] Moller EM, Bahnweg G, Sandermann H and Geiger HH. (1992). A simple and efficient protocol for the isolation of high molecular weight DNA from filamentous fungi fruit bodies and infected plant tissues. Nucleic Acids Research, 20, 6115-6116.

[36] Yaun YM and Kupfer P. (1995). Molecular phylogenetics of the subtribe Gentianinae (Gentianaceae) inferred from the sequences of internal transcribed spacers ITS of nuclear ribosomal DNA. Plant Systematics and Evolution, $196,207-226$.

[37] Christopher HJ, Kenneth JS and Harvey EBJ. (2009). Evolutionary relationship interisland biogeography and molecular evolution in Hawaiian violets (Viola:Violaceae). American Journal of Botany, 96, 2087-2099.

[38] Yan J, Deng J, Zhou CJ, Zhong BY and Hao F. (2010). Phenotypic and molecular characterization of Madurella Pseudomycetomatics sp nov a novel opportunistic fungus possibly causing black-grain Mycetoma. Journal of Clinical Microbiology, 48, 251-257.

[39] Kumar VA, Saini A and Jawali N. (2010). Phylogenetic analysis of subgenus Vigna species using nuclear ribosomal RNA ITS: Evidence of hybridization among Vinga unguiculata subspecies. Journal of Heredity, 101, $177-188$. 
Jomhe et al. / GSC Biological and Pharmaceutical Sciences 2018, 05(02), 017-025

[40] Zhang HY, He LL, Zhong HQ, Li FS, He SC and Yang QH. (2009). Identification of intergeneric hybrids between Saccharum spp. and Erianthus fulvus with ITSs. African Journal of Biotechnology, 8, 1841-1845.

[41] Qiong-xia G, Ke-hui H, Yun Y, Zhenz H and Zhen-qua WU. (2006). Phylogenetic Relationships of Sorghum and Related Species Inferred from Sequence Analysis of the nrDNA ITS Region. Agricultural Sciences in China, 5, 250256.

[42] Rodriguez-Trelles F, Tarrio R and Ayala FJ. (2000). Evidence for a high ancestral GC content in Drosophila. Molecular Biology and Evolution, 17, 1710-1717.

[43] Liu XL, Su HS, Ma L, Lu X, Ying XM, Cai Q and Fan YH. (2010). Phylogenetic relationships of sugarcane related genera and species based on ITS sequences of nuclear ribosomal DNA. Acta Agronomica Sinica, 36, 1853-1863.

[44] D'Hont A, Paulet F and Glaszmann J. (2002). Oligoclonal interspecific origin of 'North Indian' and 'Chinese' sugarcanes. Chromosome Research, 10, 253-262.

[45] Irvine JE. (1999). Saccharum species as horticultural classes. Theoretical and Applied Genetics, 98, 186-194.

[46] Devarumath RM, Kalwade SB, Kawar PG and Sushir KV. (2012). Assessment of genetic diversity in sugarcane germplasm using ISSR and SSR markers. Sugar Tech, 14, 334-344.

[47] Devarumath RM, Kalwade SB, Kulkarni PA, Sheelavanthmath SS and Suprasanna P. (2014). OMICS approaches in crop science. In: Barth D (Eds), Integrated Omics approaches in sugarcane. Taylor and Francis CRC press, NW FL, 191-250.

[48] Aljanabi SM, Honeycutt RJ and Sobral BWS. (1994). Chromosome assortment in Saccharum. Theoretical and Applied Genetics, 16, 167-172.

[49] Burnquist WL, Sorrells ME and Tankley SD. (1992). Characterization of genetic variability in Saccharum germplasm by means of Restriction Fragment Length Polymorphism RFLP analysis. Proceeding International Society of Sugarcane Technology, 21, 355-365.

\section{How to cite this article}

Jomhe FF, Thorat AS and Devarumath RM. (2018). Assessment of genetic diversity among different sugarcane genotypes using internal transcribed spacer (ITS) region of the ribosomal DNA (rDNA). GSC Biological and Pharmaceutical Sciences, 5(2), 17-25. 